CRADA Final Report

For

CRADA Number NFE-11-03544

\title{
ULTRACOATINGS - Enabling Energy and Power Solutions in High Contact Stress Environments Through Next Generation Nanocoatings
}

Peter Blau and Jun Qu

Oak Ridge National Laboratory

and

Clifton Higdon III

Eaton Corporation

Prepared by

Oak Ridge National Laboratory

Oak Ridge, TN 37831

Managed by

UT-BATTELE, LLC

for the

U.S. Department of Energy

Under contract DE-AC05-00PR2225

September 30, 2011

Approved for

Unlimited Distribution

UT-BATTELLE 


\section{DOCUMENT AVAILABILITY}

Reports produced after January 1, 1996, are generally available free via the U.S. Department of Energy (DOE) Information Bridge.

Web site http://www.osti.gov/bridge

Reports produced before January 1, 1996, may be purchased by members of the public from the following source.

National Technical Information Service

5285 Port Royal Road

Springfield, VA 22161

Telephone 703-605-6000 (1-800-553-6847)

TDD 703-487-4639

Fax 703-605-6900

E-mail info@ntis.gov

Web site http://www.ntis.gov/support/ordernowabout.htm

Reports are available to DOE employees, DOE contractors, Energy Technology Data Exchange (ETDE) representatives, and International Nuclear Information System (INIS) representatives from the following source.

Office of Scientific and Technical Information

P.O. Box 62

Oak Ridge, TN 37831

Telephone 865-576-8401

Fax 865-576-5728

E-mail reports@osti.gov

Web site http://www.osti.gov/contact.html

This report was prepared as an account of work sponsored by an agency of the United States Government. Neither the United States Government nor any agency thereof, nor any of their employees, makes any warranty, express or implied, or assumes any legal liability or responsibility for the accuracy, completeness, or usefulness of any information, apparatus, product, or process disclosed, or represents that its use would not infringe privately owned rights. Reference herein to any specific commercial product, process, or service by trade name, trademark, manufacturer, or otherwise, does not necessarily constitute or imply its endorsement, recommendation, or favoring by the United States Government or any agency thereof. The views and opinions of authors expressed herein do not necessarily state or reflect those of the United States Government or any agency thereof. 


\title{
ULTRACOATINGS - Enabling Energy and Power Solutions in High Contact Stress Environments Through Next Generation Nanocoatings
}

\author{
DOE Agreement number \\ DE-FG36-06GO16054
}

\section{CRADA Final Report}

(CRADA Number NFE-11-03544)

\author{
Peter J. Blau and Jun Qu \\ Materials Science and Technology Division \\ Oak Ridge National Laboratory \\ Oak Ridge, TN
}

in partnership with

Clifton Higdon III

Eaton Innovation Center

Southfield, MI 


\section{Foreword}

This Cooperative Research and Development Agreement (CRADA number NFE-11-03544) was effective from 15 August 2010 through 30 September 2011. Funding for the work was provided by a Grand Challenge Grant from the U.S. Department of Energy, Office of Energy Efficiency and Renewable Energy, Industrial Technologies Program (ITP), and administered by the DOE Field Office in Golden, Colorado (Mahesh Jha). Work conducted and reported in this report supported a larger project led by Eaton Corporation [DE-EE0003490, with the same title as this CRADA; namely, "Ultracoatings- Enabling Energy and Power Solutions in High Contact Stress Environments Through Next Generation Nanocoatings"]. Participants in the ORNL portion of these activities were Peter J. Blau (Principal Investigator) and Jun Qu of the Materials Science and Technology Division. This ITP Grand Challenge project also involved Ames Laboratory (AL), Borg-Warner Morse TEC, and Pratt \& Whitney Rocketdyne.

This report primarily describes friction, wear, and related investigations that were conducted on nanocoating materials supplied by AL and Eaton Innovation Center. It duplicates the information that ORNL provided for the consolidated final report that was jointly prepared by all partners. The ORNL authors acknowledge the contributions of the following individuals to this project.

Clifton Higdon, Eaton Corporation Joel Harringa, Ames Laboratory Colin Swingler, Pratt \& Whitney Rocketdyne, Inc.

No proprietary information has been included in this final report.
Bruce Cook, Ames Laboratory Yumin Wang, Borg-Warner Morse TEC 


\section{CONTENTS}

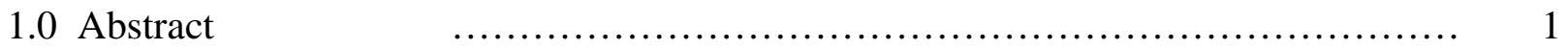

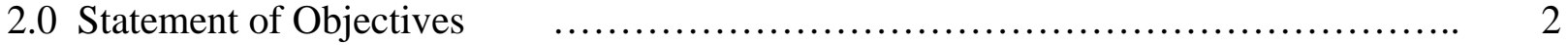

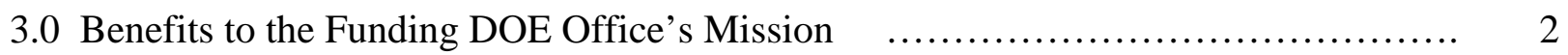

4.0 Technical Introduction, Approach, and Results of Experimental Work .............. 3

4.1 Introduction and Approach $\quad$................................... 3

4.2 ORNL Data and Results $\quad$ …..................................... 7

5.0 Subject Inventions and Publications $\quad$................................. 14

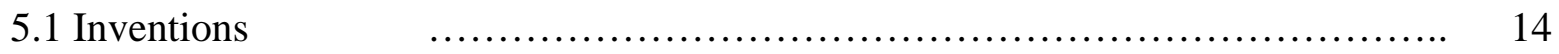

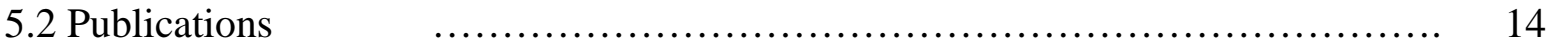

6.0 Commercialization Possibilities $\quad$................................... 14

7.0 Plans for Future Collaboration $\quad$.................................. 14

8.0 Conclusions $\quad$............................................ 15

9.0 References $\quad$................................................. 15

10.0 Symbols and Nomenclature $\quad$............................................ 16

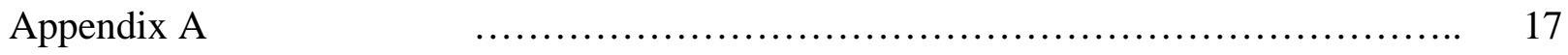




\subsection{Abstract}

This industry-driven project was the result of a successful response by Eaton Corporation to a DOE/ITP Program, Grand Challenge, industry call. It consisted of a one-year effort in which ORNL participated in the area of friction and wear testing. In addition to Eaton Corporation and ORNL (CRADA), the project team included: Ames Laboratory, who developed the underlying concept for titanium- zirconium-boron (TZB) based nanocomposite coatings; Borg-Warner Morse TEC, an automotive engine timing chain manufacturer in Ithaca, New York, with its own proprietary hard coating; and Pratt \& Whitney Rocketdyne, Inc., a dry-solids pump manufacturer in San Fernando Valley, California. This report focuses only on the portion of work that was conducted by ORNL, in a CRADA with Eaton Corporation. A comprehensive final report for the entire effort, which ended in September 2010, has been prepared for DOE by the team.

The term 'ultracoatings' derives from the ambitious technical target for the new generation of nanocoatings. As applications, Eaton was specifically considering a fuel pump and a gear application in which the product of the contact pressure and slip velocity during operation of mating surfaces, commonly called the 'PV value', was equal to or greater than $70,000 \mathrm{MPa}-\mathrm{m} / \mathrm{s}$. This ambitious target challenges the developers of coatings to produce material capable of strong bonding to the substrate, as well as high wear resistance and the ability to maintain sliding friction at low, energy-saving levels. The partners in this effort were responsible for the selection and preparation of such candidate ultracoatings, and ORNL used established tribology testing capabilities to help screen these candidates for performance. This final report summarizes ORNL's portion of the nanocomposite coatings development effort and presents both generated data and the analyses that were used in the course of this effort.

Initial contact stress and speed calculations showed that laboratory tests with available geometries, applied forces, and speeds at ORNL could not reach 70,000 MPa-m/s for the project target, so test conditions were modified to enable screening of the new coating compositions under conditions used in a prior nano-coatings development project with Eaton Corporation and Ames Laboratory. Eaton Innovation Center was able to conduct screening tests at higher loads and speeds, thus providing complementary information on coating durability and friction reduction. Those results are presented in the full team's final report which is in preparation at this writing.

Tests of two types were performed at ORNL during the course of this work: (1) simulations of timing chain wear and friction under reciprocating conditions, and (2) pin-on-disk screening tests for bearings undergoing unidirectional sliding. The four materials supplied for evaluation in a timing chain link simulation were hardened type 440B stainless steel, nitrided type 440B stainless steel, vanadium carbide (VC)-coated type 52100 bearing steel, and (ZrTi)B-coated type 52100 bearing steel. Reciprocating wear tests revealed that the VC coating was by far the most wear resistant. In friction, the nitrided stainless steel did slightly better than the other materials. 


\subsection{Statement of Objectives}

This project supports the goal of DOE's Industrial Technology Program (ITP) Advanced Materials portfolio of developing degradation-resistant materials to significantly reduce the energy intensity and/or greenhouse gas emissions of energy-intensive manufacturing industries. The objective of the current project is to "push the envelope" in surface-engineering technologies by developing next generation coating systems that will withstand severe bearing service applications. The team's ITP Grand Challenge proposal states the following objectives:

“The [new] project seeks to develop a new class of coatings that will enable use of solid lubricants in metal and ceramic-based binders. These coatings will be capable of sustaining higher load-carrying capacity than current state-of-the-art coating compositions, while maintaining low friction. Examples of applications benefiting from such technological advancements would include transmission gears, heavy-duty clutches, aerospace seals and conveyance systems, hydraulics, and automotive supercharger components. The primary technical objective is to develop one or more coating/substrate systems that will sustain a pressure-velocity (PV) product of at least 70,000 (MPa-m/s), consistent with the [chosen] applications.”

\subsection{Benefits to the Funding DOE Office's Mission}

Coatings and surface treatments are an enabling technology that affects a wide spectrum of industrial applications. Functionally, they protect surfaces from environmental degradation (corrosion), heat, and mechanical wear. In other cases, they are mainly cosmetic. Coatings and surface treatments can also lower the friction of surfaces or enable them to respond to the antiwear additives in lubricants, thereby increasing the energy efficiency of machines and specific components within them. Coating technology is a highly specialized field that addresses not only what formulations of coatings must be used to achieve the desired property goals, but also how to apply them, how thick they need to be, how effectively they adhere to the substrate, and considering cost realities, how to ensure that each batch meets quality requirements.

A coating that works well in one application, may not work in another. Therefore, it is essential to match surface engineering technology with the application. The current effort has selected several example applications having a potential impact on energy savings. One example of how coatings help to enable energy efficiency comes from Y. Wang of Borg-Warner Morse TEC [1], a partner in the ITP program of which this CRADA was a part. As shown, even a modest reduction in friction can have a large impact on energy use due to the volume of parts in use.

BW Morse TEC supplies approximately 4,000,000 timing (chain) drives per year for North American passenger cars and light trucks. It is estimated that the timing drive friction accounts for $1 \%$ of total vehicle energy use on average. Newly developed coating technologies have the potential to reduce total timing drive friction by $20 \%$ over the life of the vehicle. The EPA 
estimates that the average passenger vehicle produces 5.2 metric tons of $\mathrm{CO}_{2} \mathrm{e}\left(\mathrm{CO}_{2}\right.$ equivalent including $\mathrm{CO}, \mathrm{NO}_{\mathrm{x}}, \mathrm{SO}_{\mathrm{x}}$, etc.) or 1.42 metric tons $\mathrm{CE}$ based on mileage and annual miles driven [2]. Implementation of a newly developed chain coating could result in a total passenger car and light truck $\mathrm{CO}_{2}$ emissions reduction of approximately 40,000 metric tons per year (5.2 tons per vehicle $\mathrm{x} 4,000,000$ vehicles $\mathrm{x} 20 \%$ reduction in friction $\mathrm{x} 1 \%$ timing drive contribution). This is for engine chains in North America only and does not include transmission chains and other global markets. In addition, one gallon of gasoline is assumed to produce $8.8 \mathrm{~kg}$ of $\mathrm{CO}_{2}$ emissions based on EPA data. Therefore, the 40,000 metric tons of $\mathrm{CO}_{2}$ reduction equates to 4.31 million gallons of fuel savings.

\subsection{Technical Introduction, Approach, and Results of Experimental Work}

\subsection{Introduction and Approach}

4.1.1 Materials to be Evaluated. Ames Laboratory's recently-discovered, wear resistant coating compositions were down-selected by the project team and provided to ORNL for characterization and testing. These included $(\mathrm{Ti}, \mathrm{Zr}) \mathrm{B}_{2}$ and a proprietary vanadium carbide coating developed by Borg Warner Morse TEC. Laboratory-scale friction and wear tests were employed to measure the slipperiness and durability of candidate ultracoatings on steel substrates. Some tests were conducted at Eaton Corporation's R\&D center in Southfield, Michigan, and some at ORNL. Prior to testing at ORNL, an assessment of the requirements was conducted.

4.1.2 Milestones. The technical milestones for the one-year team effort that includes the work in this CRADA have been stated as follows:

\section{“Milestone 1.0: Demonstration of severe service wear resistance}

Development of one or more composite coating and interlayer combinations that demonstrate excellent adhesion to steel substrates, as determined by Rockwell " $C$ " indentation tests, and that show improved resistance to diamond scratch testing compared to baseline $A l M g B_{14} / \mathrm{TiB}_{2}$ composites and other industry leading materials, such as diamond-like carbon (DLC), Titanium Carbon (TiC) and Vanadium Carbon (VC). At present, there many industrial applications where the durability of components is directly affected by coating quality. Any improvements in quality will directly influence reliability, service uptime, and the amount of energy consumed during repairs."

and,

Milestone 2.0: Survival at high contact stresses in a variety of lubrication regimes

Demonstrating that the Ultracoatings selected can operate under high contact stress levels of 
150 to $300 \mathrm{ksi}$ in both lubricated and starved lubrication conditions. There is an immediate need in many energy-consuming markets for components and systems to perform at higher stresses, in spite of any environmental limitations. A coating/substrate system that can deliver a high level of performance at high contact loads in a varying degree of lubrication conditions will have a major impact."

The basic partition of effort among the team members was as follows:

- Eaton Corporation (Clifford Higdon, PI; partner in this CRADA) - Eaton had several roles, including (1) to serve as the lead project manager and coordinator for the team, (2) to prepare selected coatings by plasma-assisted physical vapor deposition , (3) to provide information on applications of interest such as gears, and (4) to conduct limited laboratory and field tests to evaluate coating performance against the project objectives.

- Ames Laboratory (Bruce Cook, PI; team member having a separate CRADA with Eaton) - Ames Laboratory suggested promising coating compositions, prepared samples for testing using pulsed laser deposition, and conducted microstructural characterizations of those samples.

- Borg-Warner Morse TEC (team member) - Provided information on applications such as automotive timing chains, and supplied samples of its proprietary vanadium carbide (VC) hard coating for comparison to the experimental compositions.

- Pratt \& Whitney Rocketdyne (Colin Swingler, PI; team member)- Provided information about a dry solids pump application where hard ultracoatings could be of significant benefit.

- Oak Ridge National Laboratory (Peter Blau, PI; CRADA partner) - Characterization of coating hardness, friction and wear behavior, and interpretation of wear results.

The following section describes ORNL contributions to the effort. Additional friction and wear tests performed by Eaton Corporation are also described in the final report presented to DOE/EERE/ITP.

4.1.2 Assessment of testing requirements. Initially, ORNL conducted an assessment of the project's target bearing conditions, as described in Section 3 The primary objective was to develop one or more coating/substrate systems that will sustain a pressure-velocity (PV) product of at least 70,000 (MPa-m/s) and/or a contact stress level of 150 to 300 kilo-pounds per square inch (ksi). According to Eaton engineers, this PV value is typical of that for transmission gear teeth. The ASME Wear Control Handbook (1980) [3] purports that the contact stresses for gear sets with a (low-cycle) fatigue life of $10^{5}-10^{7}$ cycles, treated the HRC 60, ranges from 295 to $145 \mathrm{ksi}$, which agrees with the goals stated above. The corresponding surface speeds for these pressures to achieve the PV target range from 33 to $68 \mathrm{~m} / \mathrm{s}$. The higher of the two speeds equates to 152 miles per hour. 
Various combinations of pressure and velocity required to achieve the target PV are shown in Figure 1, where for a given contact pressure, $p$, the required velocity, $\mathrm{v}_{\text {req }}$ is simply $(\mathrm{PV}) / p$. For example, at $10 \mathrm{GPa}$, the required speed is $7 \mathrm{~m} / \mathrm{s}$ to obtain $70 \mathrm{GPa}-\mathrm{m} / \mathrm{s}$, or $70,000 \mathrm{MPa}-\mathrm{m} / \mathrm{s}$. To apply such conditions during a test, one needs to find a test rig whose capabilities intersect some part of the curve. In our laboratory, the maximum achievable speed (without a lubricant in the sliding contact, and using a brake materials tester with 5 ” diameter specimens) is $15 \mathrm{~m} / \mathrm{s}$. However, with a lubricant present, our experiments are limited to a maximum speed of approximately $0.5 \mathrm{~m} / \mathrm{s}$. The contact pressure for $0.5 \mathrm{~m} / \mathrm{s}$ is $70,000 \mathrm{MPa}-\mathrm{m} / \mathrm{s} / 0.5 \mathrm{~m} / \mathrm{s}=140,000$ MPa.

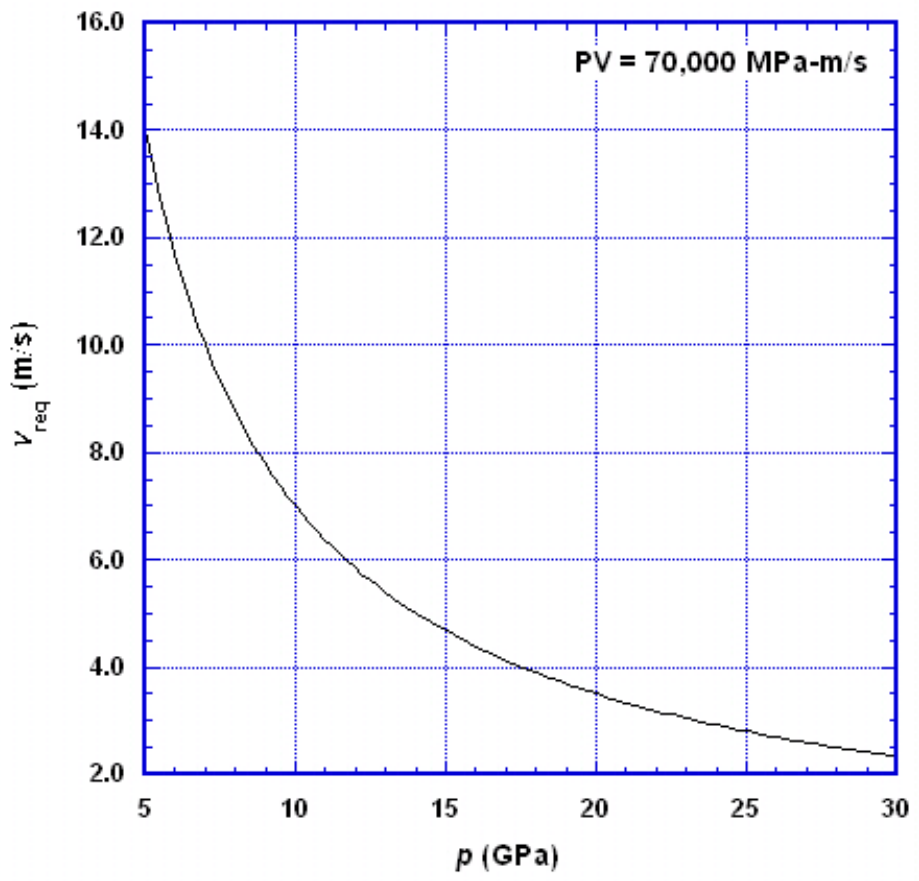

Figure 1. Combinations of pressure and velocity required for a PV product of 70,000 MPa-m/s.

Table 1 lists the contact pressures available using various non-flat configurations at ORNL. These ranges are also shown on the plot in Figure 2. Also noted on the plot, for reference, are the indentation hardness numbers for a bearing steel and two ceramics. In theory, the hardness of the nanocomposites would be higher than the $\mathrm{SiC} \mathrm{HK}$. If the bearing stress on the contact equals or exceeds the indentation hardness, then plastic deformation will surely occur, and that would invalidate the use of Hertz stress calculations which are based on elastic response [4]. Both contact pressures mentioned in the project objectives correspond to speeds in excess of 33 $\mathrm{m} / \mathrm{s}$ in order to achieve the stated PV value. 
Table 1. Contact pressures and required sliding speeds for a PV of 70,000 MPa-m/s.

\begin{tabular}{|l|c|c|}
\hline \multicolumn{1}{|c|}{ Configuration } & \multicolumn{1}{|c|}{$\begin{array}{c}\text { Elastic contact pressure } \\
\text { (Hertz contact pressure) }\end{array}$} & Required speed for PV target \\
\hline $\begin{array}{l}\text { Ball-on-flat (52100 steel), 9.525 } \\
\text { mm dia. ball, 100 N load }\end{array}$ & $2.2 \mathrm{GPa}$ & $31.8 \mathrm{~m} / \mathrm{s}$ \\
\hline $\begin{array}{l}\text { Ball-on-flat (52100 steel) } 3 \mathrm{~mm} \\
\text { dia. ball, 100 N load }\end{array}$ & $4.75 \mathrm{GPa}$ & $14.7 \mathrm{~m} / \mathrm{s}$ \\
\hline $\begin{array}{l}3 \mathrm{~mm} \text { dia. cylinder sliding } \\
\text { perpendicular on two parallel 3 } \\
\text { mm dia. cylinders (pin-on-twin), } \\
200 \text { N total load on the machine } \\
\text { (100 on each cylindrical contact) }\end{array}$ & $4.82 \mathrm{GPa}$ & $14.5 \mathrm{~m} / \mathrm{s}$ \\
\hline
\end{tabular}

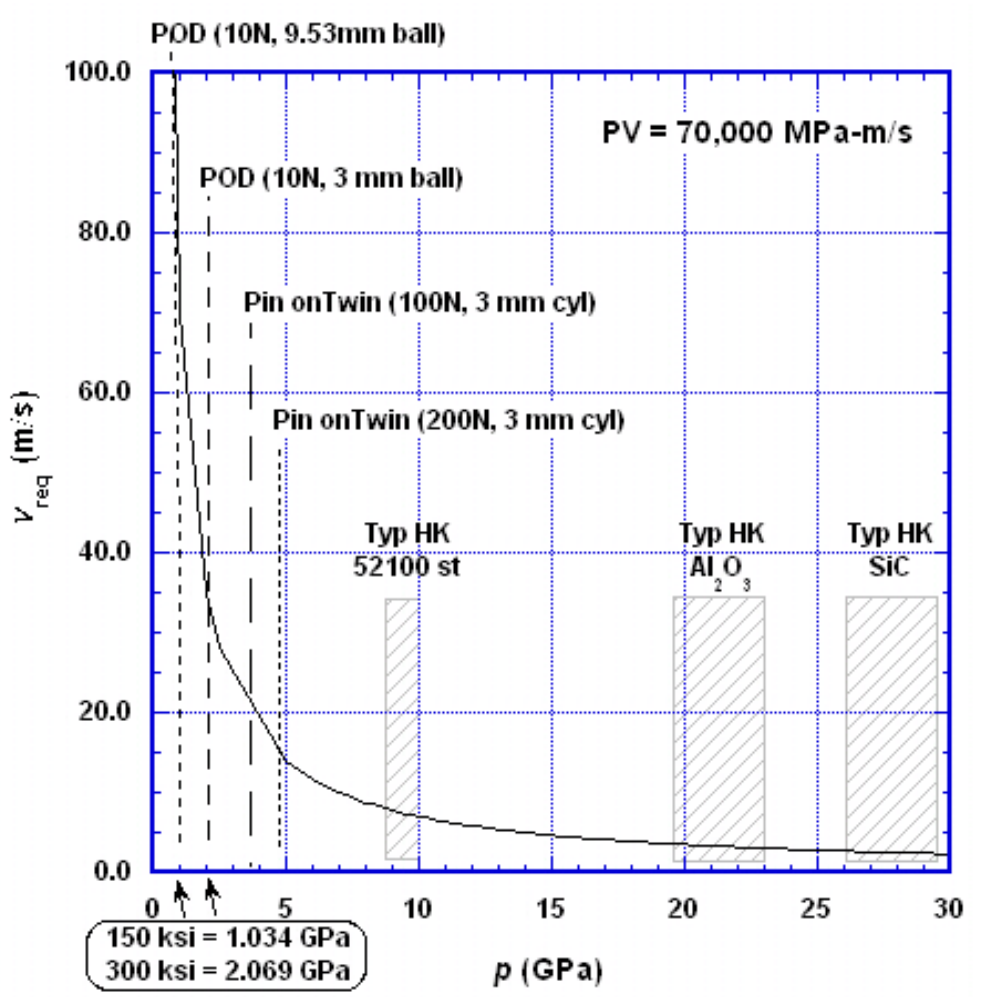

Figure 2. Comparison of material hardness (resistance to penetration) and operating conditions for ORNL tribology testing parameters with PV targets for this project.

It is impractical to use a flat contact because the force would be too high. For example, even for a small, $1 \mathrm{~mm}$ diameter circular contact, the required load would be as follows: When $p$ $=140,000 \mathrm{MPa}=1.4 \times 10^{11}\left(\mathrm{~N} / \mathrm{m}^{2}\right)$, and the area $(A)$ of a $1 \mathrm{~mm}$ diameter circle $=7.854 \times 10^{-7} \mathrm{~m}^{2}$, then required force, $N=p A=\left(1.4 \times 10^{11}\right)\left(7.854 \times 10^{-7}\right)=1.1 \times 10^{5} \mathrm{~N}$ (equivalent to $24,728 \mathrm{lb}$ f). Supplementary information provided in the Appendix to this report supports the results presented in Table 1 and Figure 2. 
From the foregoing, the target PV test conditions for the project cannot be achieved using current ORNL testing configurations. High speed was not feasible, nor was using sharp-pointed contacts which would probably penetrate any thin coating. It would appear that the Falex machine at Eaton, with its high load capacity was a better way to achieve this PV. ORNL was therefore tasked to screen the friction and wear of ultracoatings candidates using the conditions that were applied to nanocomposite coatings in the preceding effort [5].

\subsection{ORNL Data and Results}

Specimens of the coatings, on steel substrates, were subjected to several types of tests. The first work involved reciprocating wear and friction on coated chain link pins provided by Borg Warner Morse TEC. The second involved unidirectional tests of coatings on steel substrates.

4.2.1 Simulation of pins sliding on timing chain link plates. A reciprocating test apparatus (Fig. 3 ) was modified to use a cylinder-on-flat surface geometry (Fig. 4). The actual contact between the test pin and the chain link side is shown in Fig. 5. The applied load was $200 \mathrm{~N}$, the average sliding speed was $0.2 \mathrm{~m} / \mathrm{s}$ (10 cycles/s at a stroke of $10 \mathrm{~mm}$ ), and the lubricant was Mobil10W40 synthetic motor oil. The tests were conducted for a sliding distance of $400 \mathrm{~m}$ in air at room temperature.

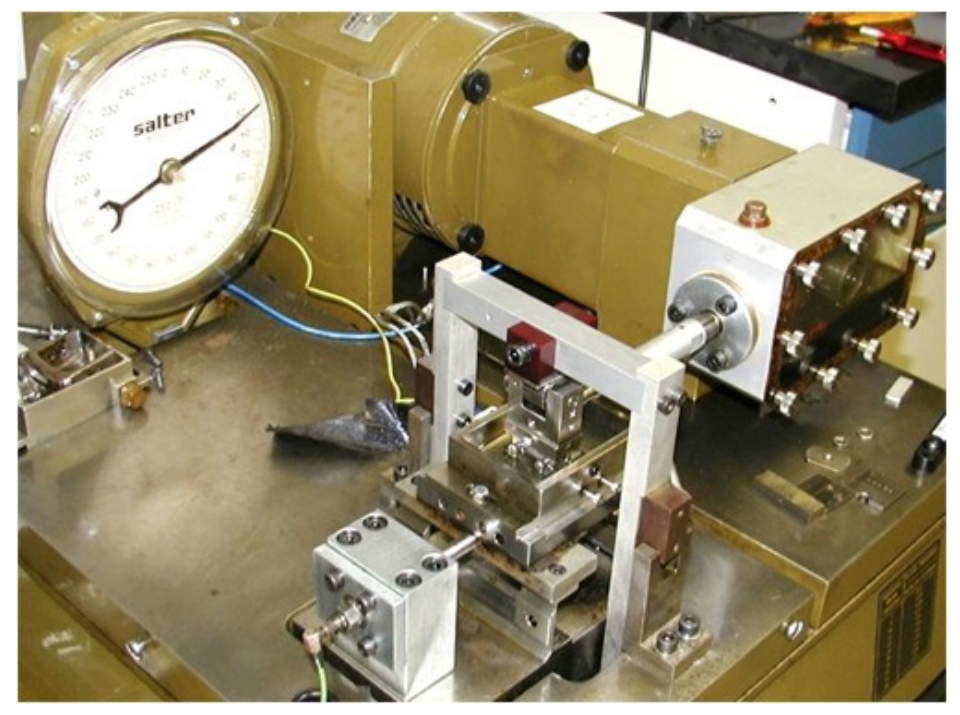

Figure 3. Model TE 77 (Phoenix Tribology, UK) reciprocating friction and wear tester used in timing chain link studies. 


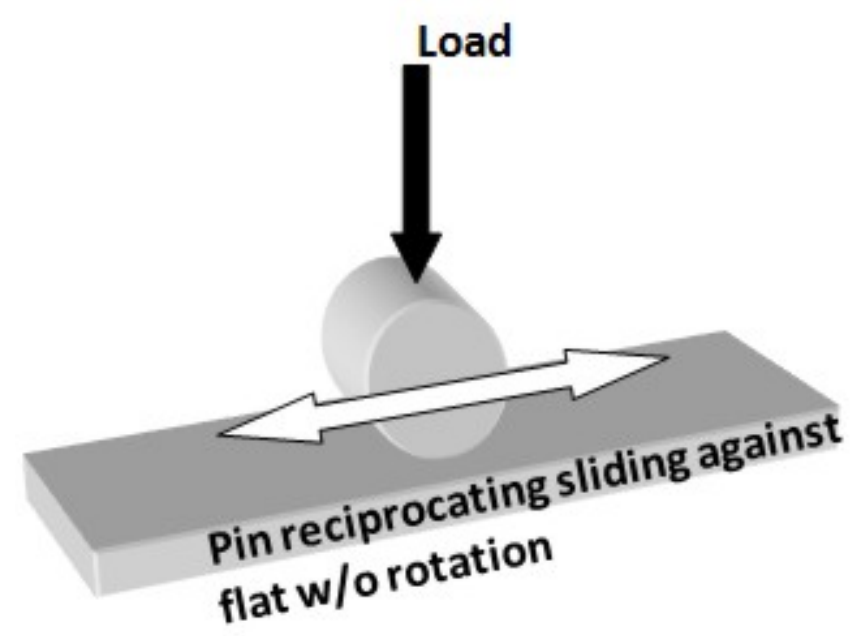

Figure 4. Schematic representation of sliding conditions.

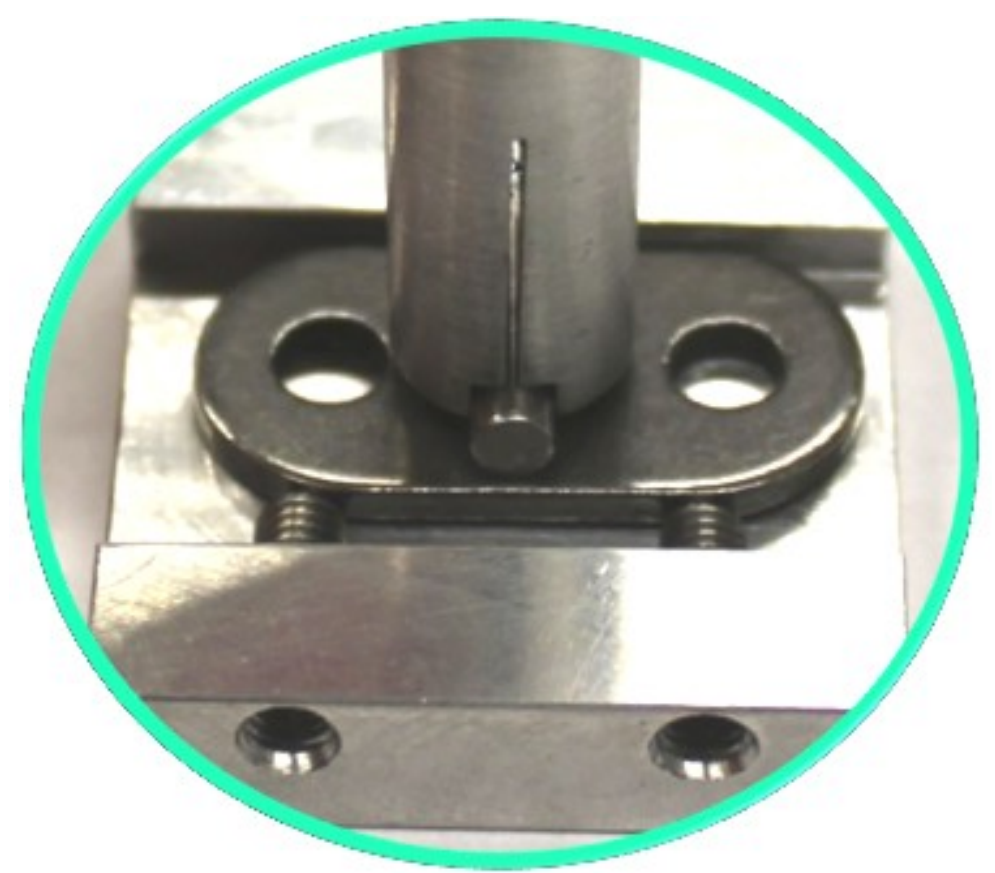

Figure 5. Close-up view of the holder containing a link pin (end of the pin can be seen in the center of the image) resting against a chain link plate specimen of hardened 1050 steel (with holes at each end). The sliding motion of the pin is horizontal in this view.

Using Hertz calculations for a cylinder on a flat (see the Appendix), the maximum and mean contact pressures at the beginning of the test are 727 and $570 \mathrm{MPa}$, respectively. The maximum speed is $0.314 \mathrm{~m} / \mathrm{s}$ at the stroke center. Therefore, the maximum PV is $228 \mathrm{MPa}-\mathrm{m} / \mathrm{s}$ and the mean PV at the stroke center was $179 \mathrm{MPa}-\mathrm{m} / \mathrm{s}$. The instantaneous rates of progression of the 
wear scar during the test are not known, but we can calculate the mean contact pressure at the stroke center at the end of the test, as shown in Table 2. The hardness and rate of wear of the VC coated pin were by far the best. The flat plates used for counterfaces were all hardened 1050 steel, but the plate used against the nitrided pin had a HV of 4.9 rather than 6.0 GPa for the other three plates.

Table 2. Results of reciprocating sliding tests.

\begin{tabular}{|l|c|c|c|c|}
\hline \multicolumn{1}{|c|}{ Pin Material or Coating } & $\begin{array}{c}\text { Hardness, } \\
\text { HV, 100 g } \\
(\mathbf{G P a})\end{array}$ & $\begin{array}{c}\text { Contact } \\
\text { Pressure, } \mathbf{P} \\
\mathbf{( M P a )}\end{array}$ & $\begin{array}{c}\text { PV product } \\
\mathbf{( M P a - m / s )}\end{array}$ & $\begin{array}{c}\text { Wear Scar } \\
\text { Width, pin } \\
(\boldsymbol{\mu m})\end{array}$ \\
\hline Hardened 440B stainless steel & 6.9 & 59.7 & 18.8 & 335 \\
\hline VC-coated 52100 steel & 28.6 & 250. & 78.5 & 80 \\
\hline (TiZr)B-coated 52100 steel & 17.4 & 66.7 & 20.9 & 300 \\
\hline Nitrided 440B stainless steel & 12.7 & 71.4 & 22.4 & 280 \\
\hline
\end{tabular}

The appearances of the worn test pins are shown in Figure 6(a-d). The narrow wear scar on the VC coated pin is suggestive of its high hardness and that the surface treatment remained intact. The (ZrTi)B pin showed signs of wear-through, and the wear scar width is only slightly narrower than that for the hardened 440B pin without treatment.

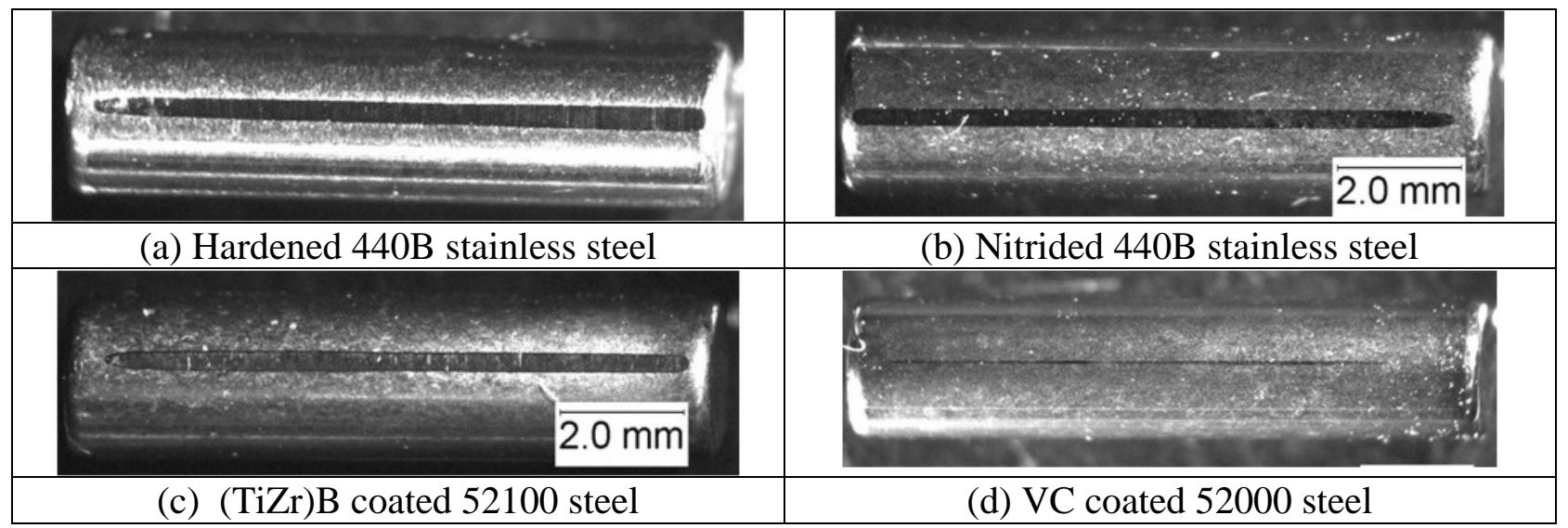

Figure 6. Wear markings on test pins used in lubricated reciprocating tests. Note that the nitrided pin (b) was run again a plate specimen of slightly lower hardness than the others. Magnifications are the same for all images. 
Figure 7 shows that the friction coefficients during sliding were about 0.09 to 0.12 . This is within the boundary lubrication regime and suggests that there was a measure of material contact. The nitrided steel pin exhibited slightly lower friction at the end of the test, but the reasons were not entirely clear. After a noisy interval between 120 and $180 \mathrm{~m}$ of sliding distance, the decrease in friction began, suggesting that the noisy interval indicated abrasive wear which eventually polished the surface and allowed the friction to begin to drop.

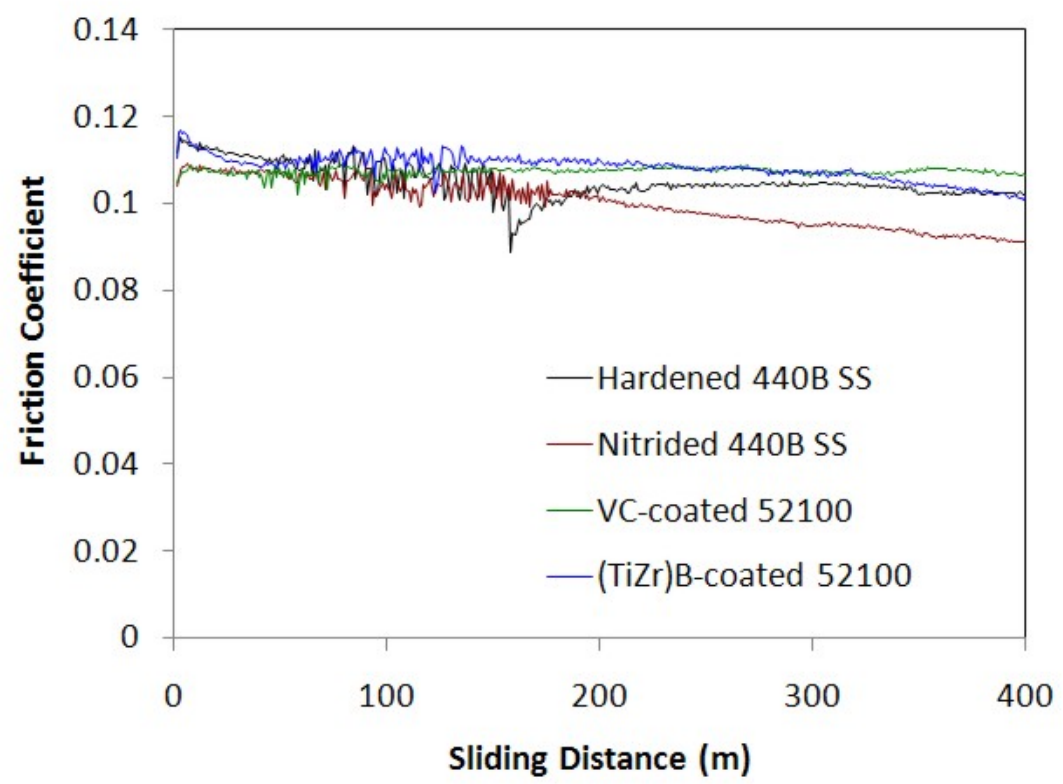

Figure 7. Friction coefficient versus cumulative sliding distance for various pin materials sliding against hardened 1050 steel.

4.2.2 Pin-on-disk tests. Work on a prior coatings development project including Eaton, Ames Laboratory, and ORNL, involved the use of a pin-on-disk type friction and wear apparatus [5]. The same test method was employed here for the purposes of comparing the tribological characteristics of pulse-laser-deposited (PLD) coatings of (ZrTi)B on M2 steel substrates, but with different deposition times at $500^{\circ} \mathrm{C}$. One nanocoating was deposited for $10 \mathrm{~min}$, the other for 20 min. Specimens were provided by Ames Laboratory.

The pin specimen was an AISI 52100 bearing steel ball, $9.525 \mathrm{~mm}$ diameter. The normal load was $10 \mathrm{~N}$, the sliding speed was $0.5 \mathrm{~m} / \mathrm{s}$, and tests were performed at room temperature in air using Mobil DTE-24 as the lubricant (3 drops added at the start). The sliding period was 6 hours (10800 m sliding distance).

Figure 8 compares the friction coefficient versus sliding distance behavior for the two PLD films. Each plotted point was the average of 2 seconds of sampled data acquired every minute. Data acquisition zeroing was done immediately before testing each time to ensure ability to see slight differences in frictional behavior. The 20 min processing time produced a very slightly higher friction coefficient than for 10 minutes, but that small a difference was not felt to be significant. 
More detailed frictional behavior during the first 2 seconds after start for both runs is shown in Figure 9 . The two traces were off-set by a friction coefficient of 0.5 to avoid overlapping the plots. The start-up behavior was for all practical purposes identical, with the periodic frictional variations corresponding to one revolution of the disk $(0.063 \mathrm{~s} / \mathrm{rev}$ at this speed and wear track diameter).

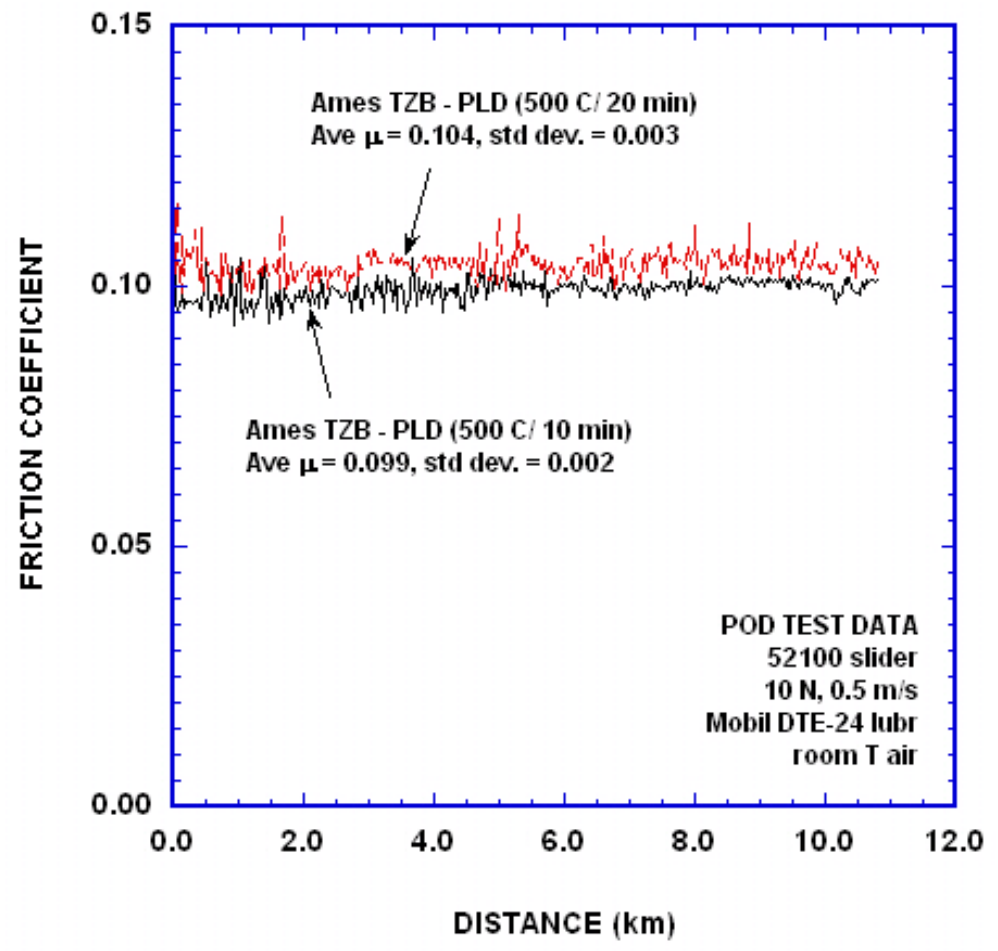

Figure 8. Variation in interval friction coefficients with sliding distance on the pin specimen. 


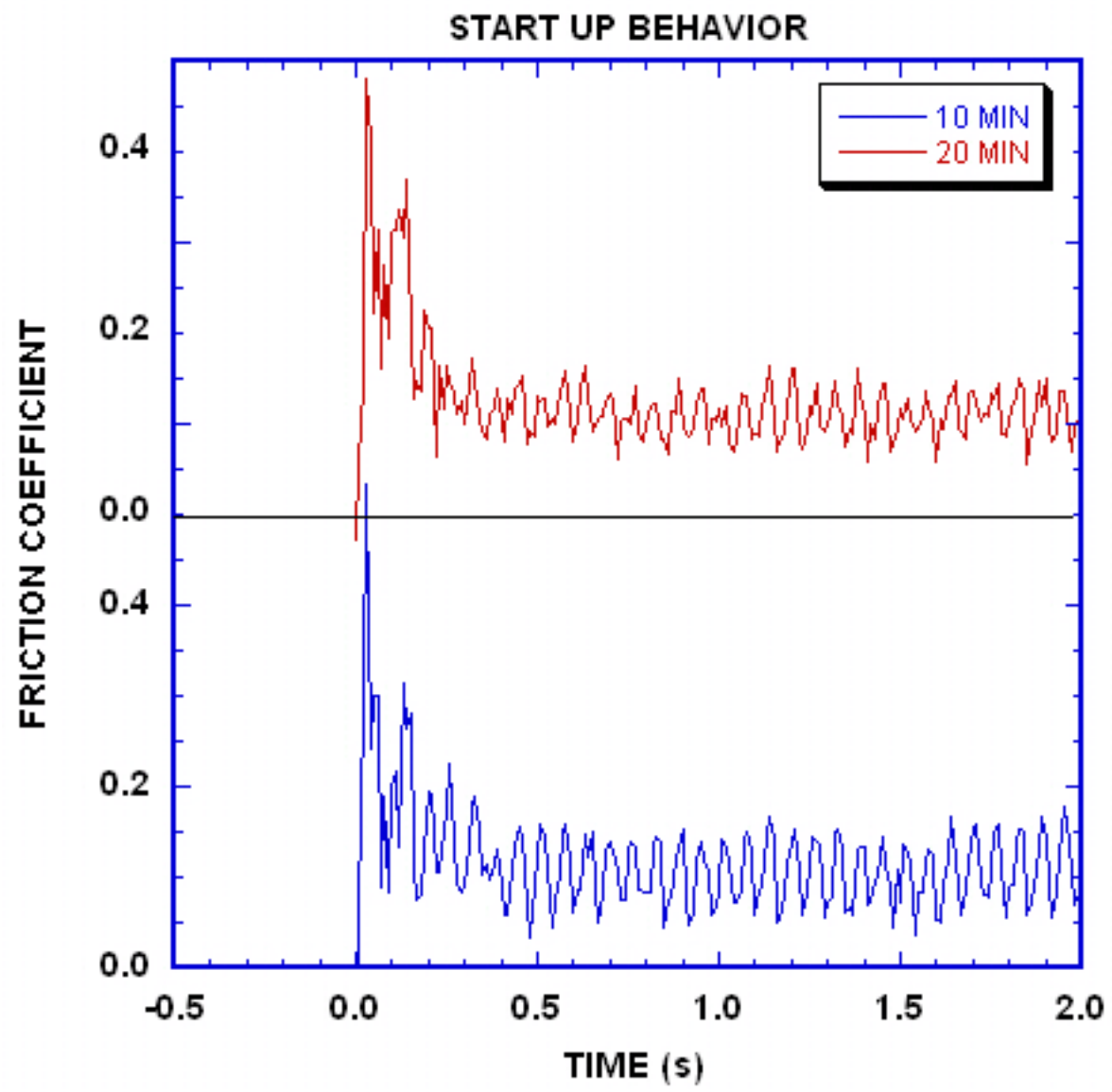

Figure 9. Comparison of the starting frictional behavior for two PLD runs. The inset at the upper right indicates PLD exposure time.

Images of the ball and disk specimens after each run are shown in Figures 10 and 11 . The track from the specimen with the shorter processing time [see Fig. 10(b)] was smoother and narrower than that of the other specimen. It showed none of the periodic delamination pits exhibited by the 20 min processing time (Fig. 11(b)). The greater track roughness can decrease the lubricant film thickness to roughness ratio (a.k.a. the $\Lambda$-ratio) and therefore may have produced a slightly higher friction coefficient. 


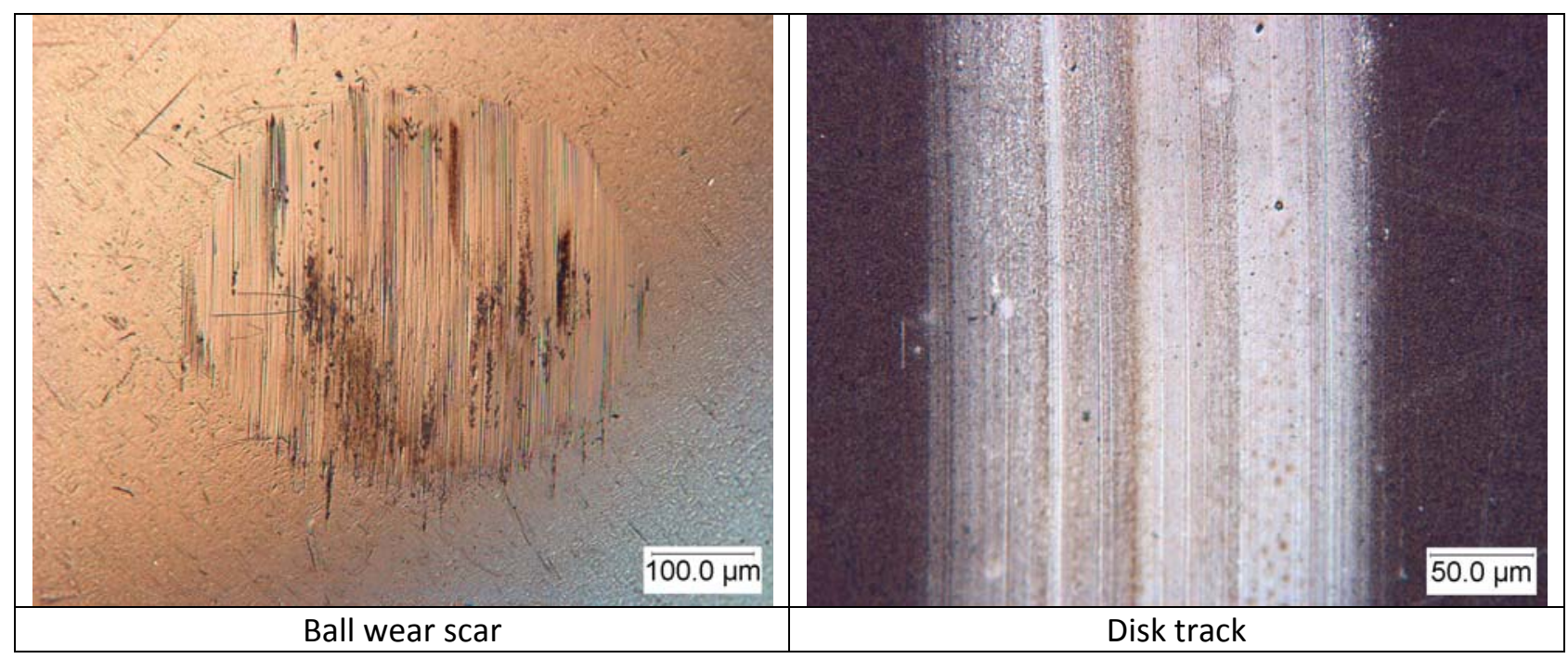

Figure 10. Ball wear scar (left) and disk track (right) for the 10 min PLD specimen.

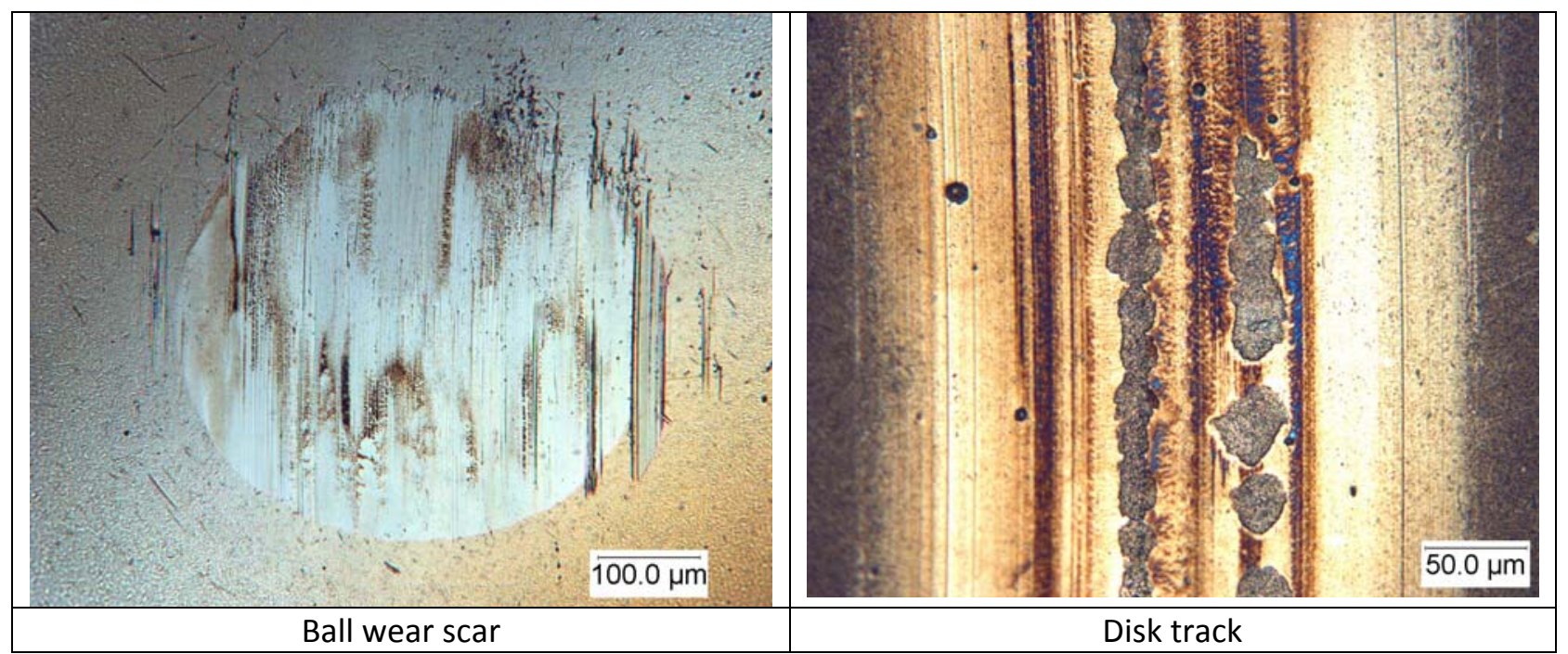

Figure 11. Ball wear scar (left) and disk track (right) for the 20 min PLD specimen.

Wear rates were calculated for the ball based on the length and width of the scar using the average diameter and the presumption of a hemispherical cap. For the disk, volumetric wear rate was calculated from the average depth of the wear track and the track diameter. As shown in Table 3, the 20 min PLD specimen wore more than the 10 min PLD specimen, and the 20 min specimen also exhibited delamination suggesting insufficient coating-substrate adherence. 
Table 3. Wear Rates (WR) of Balls and Disks

\begin{tabular}{|c|c|c|c|}
\hline Test ID & Disk ID & $\begin{array}{c}\text { Ball WR } \\
\left(\mathrm{mm}^{3} / \mathrm{N}-\mathrm{m}\right)\end{array}$ & $\begin{array}{c}\text { Disk WR } \\
\left(\mathrm{mm}^{3} / \mathrm{N}-\mathrm{m}\right)\end{array}$ \\
\hline ST1_PB_100 & TZB on M2 (PLD 500C/10 min) & $3.17 \times 10^{-9}$ & $1.40 \times 10^{-8}$ \\
\hline ST1_PB_101 & TZB on M2 (PLD 500C/20 min) & $4.48 \times 10^{-9}$ & $2.14 \times 10^{-8}$ \\
\hline
\end{tabular}

In light of the uncertainties of repeatability for the materials evaluated here, and that variability in tribotests is dependent on materials, equipment, and other factors, it cannot be stated with certainty that the magnitude of WR in Table 3 is truly different between the two coatings.

\subsection{Subject Inventions and Publications}

\subsection{Inventions}

None

\subsection{Publications}

None

\subsection{Commercialization Possibilities}

Phase III of the larger program of which this CRADA was a part involved conducting detailed studies of costs and commercialization-related issues. These tasks were undertaken by Eaton Corporation, and indicated the technical and cost feasibility of incorporating AMB nanocomposite coatings in several products including hydraulic and aircraft fuel pumps.

Penetration into the various markets remains to be established, but there is growing interest within Eaton on applying the coatings to a number of product lines, like fuel pumps, where the $(\mathrm{Ti}, \mathrm{Zr}) \mathrm{B}_{2}$ coatings produced encouraging results in component tests. The final report for the team, prepared by Eaton Corporation, contains a more detailed description of the marketing of the nanocomposite-coated components.

\subsection{Plans for Future Collaboration}

In the spring of 2010, Eaton Corporation, Ames Laboratory, Oak Ridge National Laboratory, Borg-Warner Morse TEC, and Pratt \& Whitney Rocketdyne (PWR), proposed and were awarded an DOE, Industrial Technologies Program, Grand Challenge project titled "Ultracoatings Enabling energy and power solutions in high contact stress environments through next generation nanocoatings." It drew on the strong collaborations from the past to extend coating technology in new directions that are aimed at more severe bearing applications. Furthering our team effort, Eaton, ORNL, and others are teaming to respond to a 2011 ITP call for proposals that will extend this work in new directions in surface engineering and materials development. 


\subsection{Conclusions}

Conclusions are based upon two types of friction and wear tests: (1) simulations of timing chain wear and friction under reciprocating conditions, and (2) pin-on-disk screening tests for bearings undergoing unidirectional sliding. The four materials supplied for evaluation in a timing chain link simulation were hardened type 440B stainless steel, nitrided type 440B stainless steel, VCcoated type 52100 bearing steel, and (ZrTi)B-coated type 52100 bearing steel. Reciprocating wear tests revealed that the VC coating was by far the most wear resistant. In friction, the nitrided stainless steel did slightly better than the other materials.

Pin-on-disk tests of AISI 52100 bearing steel sliding on TiZrB coatings on M2 tool steel in Mobil DTE-24 hydraulic fluid revealed that a longer exposure to pulsed laser deposition (20 min) actually resulted in more spalling of the coating and a higher wear rate than did the coating produced with only 10 min PLD, suggesting that a thinner deposit may have lower residual stress and be more durable.

\subsection{References}

1. Y. Wang, Borg Warner Morse TEC, Itaca NY, personal communication (2011).

2. EPA420-F-05-004, Emission Facts - Greenhouse Gas Emissions from a Typical Passenger Vehicle, http://www.epa.gov/oms/climate/420f05004.pdf

3. W. O. Winer and M. B. Peterson, ed. (1980) Wear Control Handbook, ASME, New York, p. 772.

4. W. C. Young (1989) Roark’s Formulas for Stress and Strain, $6^{\text {th }}$ ed., McGraw-Hill Book Co., New York, p. 650.

5. C. B. Higdon III (2010) "Nanocoatings for High-Efficiency Industrial Hydraulic and Tooling Systems,” Final Report, Eaton Corporation, December 31, 2010. 227 pp. 


\title{
10.0 Symbols and Nomenclature
}

\section{Symbols}

$\begin{array}{ll}\mu & \text { friction coefficient (see also COF) } \\ H V & \text { Vickers microindentation hardness } \\ P & \text { applied (normal) load (also designated as } w \text { in film thickness calculations) }\end{array}$

\section{Nomenclature}

\author{
$\mathrm{Al}_{2} \mathrm{O}_{3} \quad$ alumina (cermic) \\ COF alternative abbreviation (to Greek $\mathrm{mu}$ ) for the coefficient of friction \\ CRADA Cooperative Research and Development Agreement \\ HK Knoop microindentation hardness number \\ HV Vickers microindentation hardness number \\ ITP Department of Energy IndustrialTechnologies Program \\ M2 a tool steel alloy used as a substrate for coating studies \\ ORNL Oak Ridge National Laboratory \\ PLD pulsed laser deposition, method of coating used by Ames Lab \\ POD pin-on-disk tribotest geometry \\ PV product of the nominal contact pressure on a bearing and the relative sliding velocity \\ of the mating surfaces \\ PVD physical vapor deposition \\ RCOF reciprocating cyinder-on-flat specimen tribotest geometry \\ RT room temperature \\ $\mathrm{SiC} \quad$ silicon carbide (ceramic) \\ VC vanadium carbide \\ WR wear rate (volume removed per unit sliding distance per unit applied load) \\ $\Lambda$-ratio in lubrication theory, the ratio of the lubricant film thickness to the composite \\ roughness of the two facing bearing surfaces
}




\section{Appendix A. Supplementary Information on Bearing Pressure Calculations}

\section{1) Conversion factors:}

\begin{tabular}{|c|c|c|}
\hline Convert from & To & Multiply by \\
\hline \hline $\mathrm{N}$ & $\mathrm{lb}-\mathrm{f}$ & 0.2248 \\
\hline $\mathrm{ksi}$ & $\mathrm{MPa}$ & 6.895 \\
\hline $\mathrm{m} / \mathrm{s}$ & $\mathrm{ft} / \mathrm{min}$ & 196.85 \\
\hline $\mathrm{MPa}$ & $\mathrm{ksi}$ & 0.1450 \\
\hline $\mathrm{MPa}-\mathrm{m} / \mathrm{s}$ & $\left(\mathrm{N} / \mathrm{m}^{2}\right)-(\mathrm{m} / \mathrm{s})$ & $1.0 \times 10^{6}$ \\
\hline $\mathrm{psi}-\mathrm{sfm}$ & $\mathrm{MPa}-\mathrm{m} / \mathrm{s}^{*}$ & $3.506 \times 10^{-5}$ \\
\hline \multicolumn{2}{|c}{} \\
\hline
\end{tabular}

* $(\mathrm{lb} / \mathrm{in} \wedge 2)(\mathrm{in} / 0.0254 \mathrm{~m})^{2}(0.454 \mathrm{~kg} / \mathrm{lb})(9.807 \mathrm{~N} / \mathrm{kg})(0.3048 \mathrm{~m} / \mathrm{ft})(\mathrm{min} / 60 \mathrm{~s})=35.06 \mathrm{~Pa}-\mathrm{m} / \mathrm{s}=>3.506 \mathrm{x}$ $10^{-5} \mathrm{MPa}-\mathrm{m} / \mathrm{s}$

2) PV goals (in SI and customary units):

$$
7 \times 10^{4} \mathrm{MPa}-\mathrm{m} / \mathrm{s} \times\left(10^{6} \mathrm{~N} / \mathrm{m}^{2}\right) / \mathrm{MPa}\left(=7 \times 10^{10} \mathrm{~N} / \mathrm{m}^{2}-\mathrm{m} / \mathrm{s}\right) \text { equates to } 2 \times 10^{9} \mathrm{psi}-\mathrm{sfm}
$$

\section{3) Contact Stress Targets:}

\begin{tabular}{|c|c|c|}
\hline $\begin{array}{c}\text { Target Pressure } \\
(\mathbf{k s i})\end{array}$ & Target (MPa) & Equivalent (N/m $\mathbf{2})$ \\
\hline \hline 150. & 1034. & $1.034 \times 10^{9}$ \\
\hline 300. & 2069. & $2.069 \times 10^{9}$ \\
\hline
\end{tabular}

\section{4) Hertz (fully elastic) Contact Stress on a Ball:}

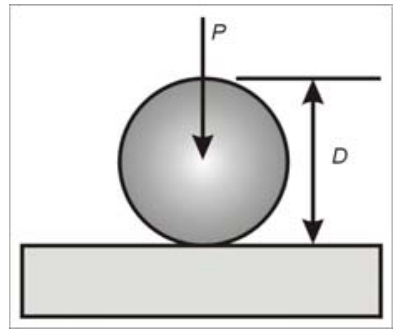

Required normal force (load) on a D = $9.525 \mathrm{~mm}$ diameter 52100 steel ball / 52100 steel plane combination that is required to produce $150 \mathrm{ksi}$ or $300 \mathrm{ksi}$ Hertz contact stress:

\begin{tabular}{|c|c|c|}
\hline $\begin{array}{c}\text { Target Pressure } \\
\text { (ksi) }\end{array}$ & $\begin{array}{c}\text { Required Force, } \mathbf{P} \\
\text { (N) }\end{array}$ & $\begin{array}{c}\text { Required Force } \\
\text { (kg-f) }\end{array}$ \\
\hline 150. & 10.38 & 1.058 \\
\hline 300. & 83.24 & 8.485 \\
\hline
\end{tabular}




\section{5) Speed requirements}

Speeds required to achieve the target PV of $70 \mathrm{GPa}-\mathrm{m} / \mathrm{s}$ at the two given target pressures

\begin{tabular}{|c|c||c|c|}
\hline $\begin{array}{c}\text { Target Pressure } \\
\text { (ksi) }\end{array}$ & $\begin{array}{c}\text { Target Pressure } \\
\left(\mathbf{N} / \mathbf{m}^{\mathbf{2}} \mathbf{)}\right.\end{array}$ & $\begin{array}{c}\text { Required } \\
\text { Velocity } \\
\mathbf{( m / s )}\end{array}$ & $\begin{array}{c}\text { Required } \\
\text { Velocity } \\
\text { (mph) }\end{array}$ \\
\hline \hline 150. & $1.034 \times 10^{9}$ & 67.70 & 151.2 \\
\hline 300. & $2.069 \times 10^{9}$ & 33.83 & 75.6 \\
\hline
\end{tabular}

